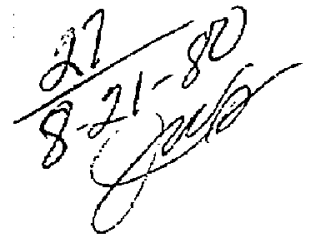

\section{STRESSMETER PLACEMENT AT SPENT FUEL TEST IN}

CL IMAX GRANITE

A. E. Abey

H. R. Washington

UCDD- 18629

May 20, 1980

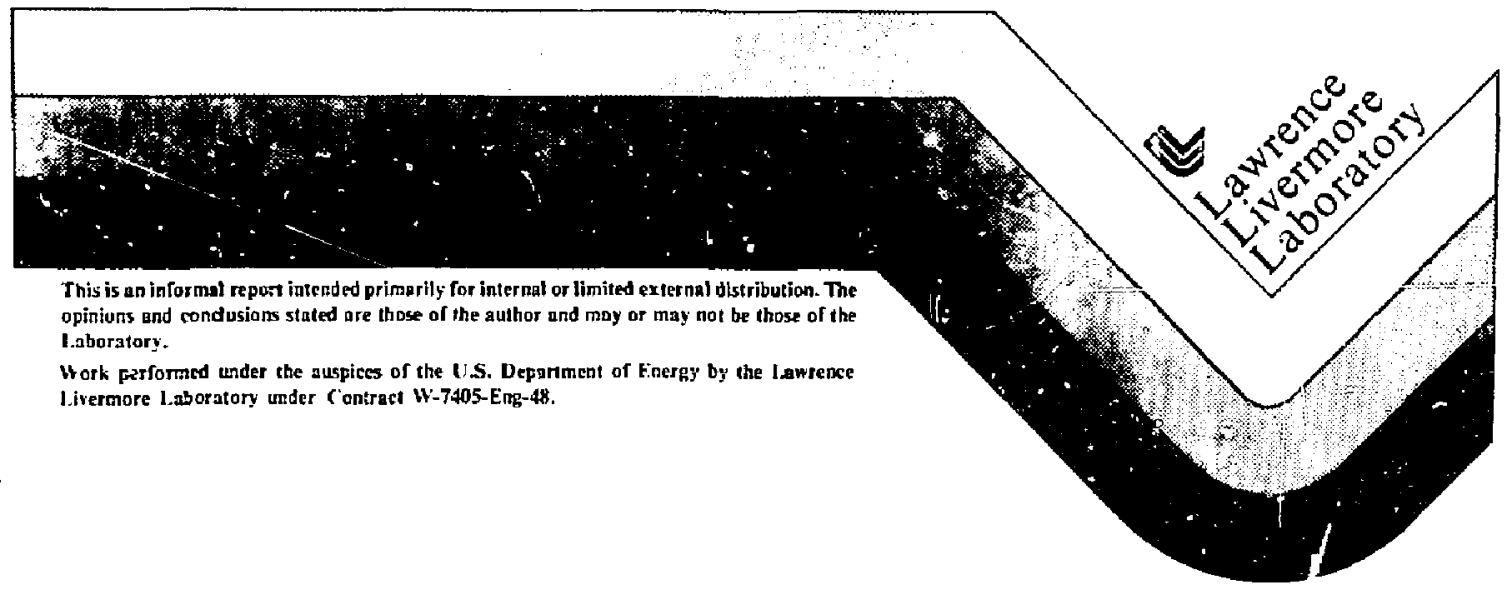

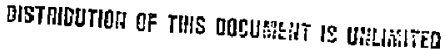




\section{ABSTRRCT}

Vibrating wire stressmeters were installed in the Spent fuel Facility at the Nevada Test Site. These stressmeters will measur the changes in in situ stress during the five-year spent fuel test. Before installation, laboratory tests were conducted to study reproducibility of placer nt and to develop a program hopefully to reduce corrosion of the stressmeters while in place at the Spent Fuel Facility. These laboratory tests are discussed along with the installation of the stressmeters at the Spent Fuel Facilit .

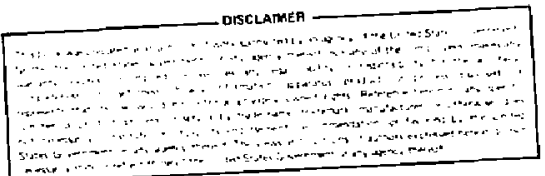

4 
A test of retrievable dry geologic storage of spent fuel assemblies from an operating commercial nuclear reactor is under way at the Nevada Test Site of the U.S. Department of Energy (DOE $)^{l}$. This project, generally referred to as the "spent fuel test--Climax granite," is part of the DDE Nevada Nuclear Waste Storage Investigations, which are managed by the Nevada Operations Office of the DOE. The Lawrence Livermore National Laboratory (LLNL) is responsible for the technical direction of the test. This generic test is located $420 \mathrm{~m}$ below the surface in the climax granite stock. Eleven canisters containing spent fuel assemblies approximately 2.5 years out of reactor core will be emplaced in the floor of a storage drift along with six electrical simulator canisters and their effects will be compared. Two adjacent parallel drifts will contain electrical heaters that will be operated to simulate within the test array the thermal field of a large repository. During the test thermomechanical data will be obtained that may ultimately be useful in designing a spent fuel repository in granite or other hard rock.

As a part of the scientific instrumentation program associated with the spent fuel test, stressmeters were placed in a pillar and in the floor of the underground facility. The pillar and floor are of granite and are what remained after the mining of the canister and heater drifts. The stressmeters were placed in these rock volumes to monitor the changes in in situ stresses during the progress of the spent fuel test. 
The stressmeters were developed ${ }^{2}$ as an engineering device to monitor, primarily for safety reasons, the changes in in situ stress around underground installations. The stressmeters are manufactured by IRAD CACE, Inc., and have a number of advantages for field work, not the least of which is their basic principle of operation. With these gauges the applied stress is related to the frequency of a vibrating wire, and voltages, lead resistance, etc., are not important.

We investigated two areas relating to the use of these stressmeters prior to placing them at the Spent Fuel Facility. The first concern related to our ability to place stressneters in various borehoies and to obtain a predictable stress calibration from one stressmeter placement to another. The second concern came to light when stressmeters used in an earlier short term in situ test in the Spent Fuel Facility were recovered and examined. These stressmeters were in place about three months and showed a significant amount of corrosion. We believed that unless the corrosion could be greatly reduced the validity of the data from the stressmeters during the five-year duration of the spent fuel test could not be supported.

The work done in these two areas will be discussed in the following pages. The placement of the stressmeters at the Spent Fuel Facility will ilso be covereo in some detail. 


\section{CALIBRATION REPRODUCIBILITY}

The IRAD stressmeters yield the stress applied to the stressmeter body by measuring the period of vibration of a wire held in tension by the stressmeter body (Fig. I). When the stressmeter j,s assembled, the wire is installed under tension. The tension determines the zero load period of vibration, and to be acceptable must fall within a range of values. The stress is transmitter to the stressmeter body through the wedge-platen combination. The transmitted load deforms the stressmeter body, and changes the tension and, tharefore, the period of the vibrating wire.

The stressmeter is preloaded to a given stress level during installation by pulling the wedge parallel to the axis of the stressmeter. This action forces the platen against the borehole wall. As the in-situ stress on the stressmeter increases or decreases, the period of vibration will change from the preload value.

The question of stressmeter calibration is related to how well the three stressmeter parts are aligned. The situation one wants is uniform loading along these parts with the load parallel to the viorating wire. This uniform loacing is the case if the stressmeter placement yields a mirror syminetry plane along the axis of the stressmeter and parallel to the vibrating wire. IRAD GAGE has shown that this situation can well be approximated in stressmeter placements in its laboratory ${ }^{3}$.

In our studies we carried out a number of stressmeter placements in a setup designed to simulate field conditions for stressmeter placements. A smooth 38-mm-diam borehole was drilled in a granite cube approximately 


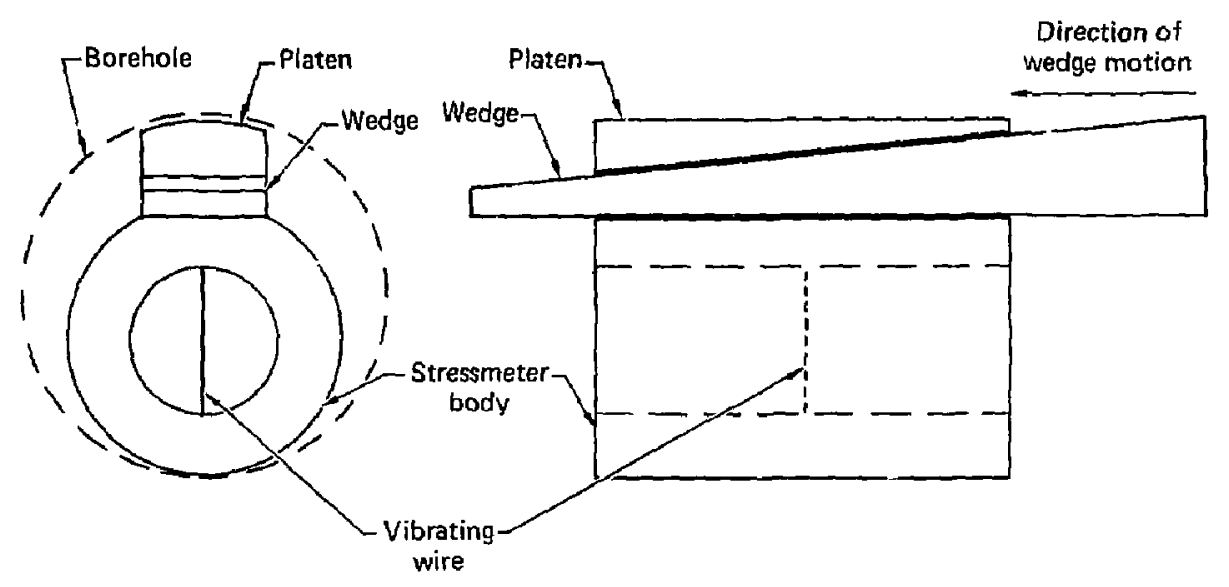

FIG. 1. Schematic of stressmeter in borehole. 
$120 \mathrm{~mm}$ on a side. A $1-m$ long metal tube with a 38-num i.d. was aligned with the hole in the cube and was firmiy attached to it. Inis simulated borehole corresponded to the shortest and, therefore, easiest stressmeter placement to be attempted in the field.

Great care was used to make all placements in this setup as nearly identical as possible. The anly intentional difference in the placements was a rotation of $\pi^{*}$ about the axis for the stressmeter in approximately one-half of the settings. There were no systematic differences between the placements for rotations by $\pi$; however, there were differences in calibration from placement to placement. The calibrations were obtained by loading the cube in a hydraulic press. The load was applied to the two opposite surfaces that are perpendicular to the vibrating wice. With a cube loaded in this manner, the state of stress in and around the stressmeter is complex. However, the stress state snould have been the same for each calibration because the load on the surface was never allowed to go to zero. A stress of $31.5 \times 10^{5}$ Pa was applied and maintaines on the cube surfaces during the stressmeter installations.

The differences in calibration obtained for some placements are distinct from the slight changes in calibration that occurred with repeated stress loading and unloading cycles for a given stressmeter placement. Two distinct calibration curves were found. One of these calibrations could be correlated

*Angles in radians. 
with a substantial drop in stressmeter preload (applied by pulling the wedge) when the installation tool was removed; the cther could be ccrrelated with little drop in prelcad. The installation tnol holds the stressmeter body-wedge-platen assembly in alignment duriig the wedge pulling. (Our installation tool had been modified to impruve this aligrment.) After the inscallation tool is removed from the set stressmeter assembly, the wedge and platen can move relative to the stressmeter body. This can happen ever thaugh the assembly is under preload if the stress differences between the actual stress state and the desired symmetric state are large enough. These stress differences can result from, for example, borehole surface roughness, a failure surface in the borehole wali at the location of the stressmeter, a nonuniform borehole diameter, a nonstraight borehole, grains of different materials at the stressmeter contacts, errors in alignment of the assembly along borehole axis, etc. If the shift in alignment occurs, changes in in situ stress are not transmitted to the stressmeter body in the same manner; i.e., the body is loaded differently. This results in the vibrating wire responding differently to changes in apflied stress.

When the stressmeter output dropped iess than 10\% of the preluad upon removal of the installation tool, we obtained what is termed a "normal"calibration. The data for a setting with a normal calibration appear in Fig. 2a. For drops of greater than 10\% upon tool withdrawal, a second calibration, termed "subnormal," was obtained. Approximately 30\% less sensitive than the normal calibration, this calibration appears in Fig. 20. The 10\% drop that delineates the two calibrations is not sharp and is somewhat arbitrary but appears to be a useful dividing line. What calibrations should be applied to stressmeters installed in the Spent Fuel Facility will be discussed later in the section "Stressmeter Installation at the Spent Fuel Faciljty." 


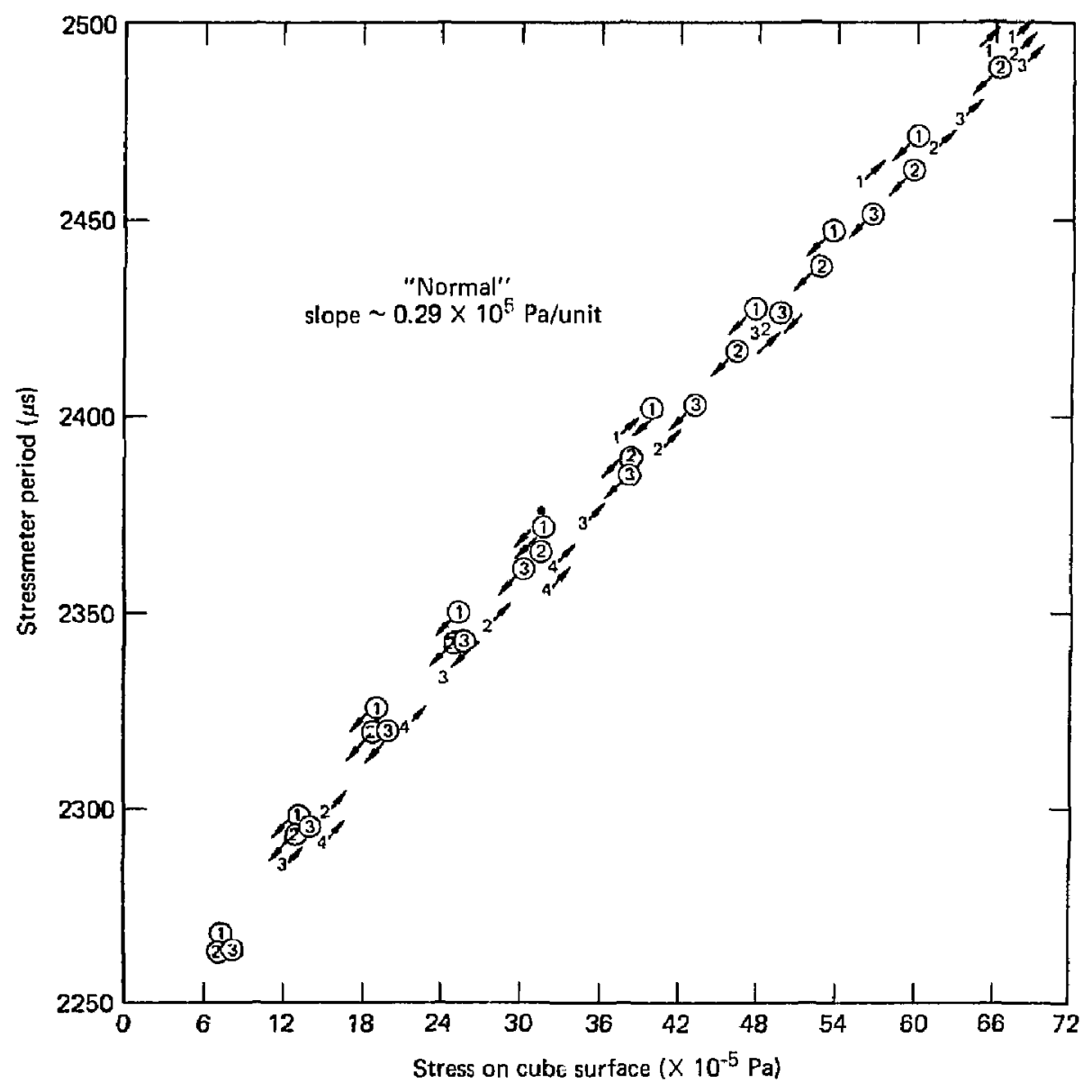

FIG. 2a. "Nermal" calibrations for laboratory tests in granite cube. 


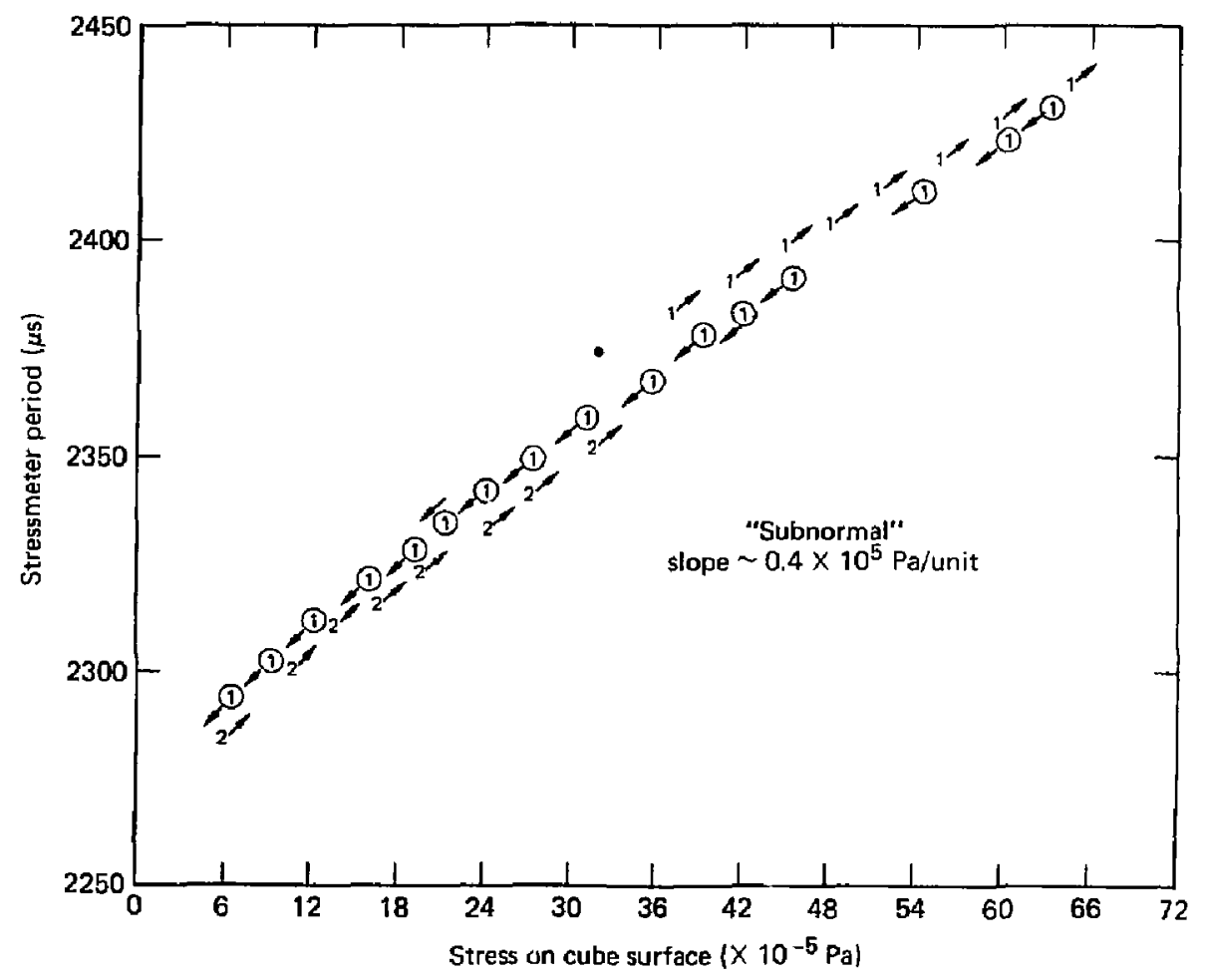

FIG. 2b. "Subnormal" calibrations for laboratory tests in granite cube. 
CLRROSION FHSISTANCE

One of the stressmeters used in th: earlier in situ experiments is shown in Fig. 3. This stressmeter has been sondbiasted to remove a layer of corrosion "giesstimateu" to be a tew ', ndreds of a millimeter thick. The pits that remainea $x^{\circ}$, wh to $i .75$ int: deep. It is yifficuit to predict the effect

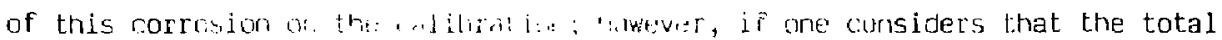

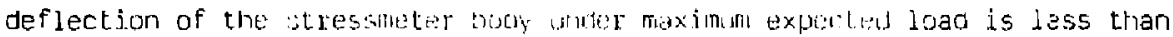
$10^{-2} \mathrm{~cm}$, a corrosiun hayer of this thickness coull hedve an impcrtant effect on the stressmeter calibration.

The corrosion pits will also influstre the effective inodulus of the stressmeter body and, thereby, the aniouri nf idefornlation fi.t a given load. If the rate of corrusion were more or iess constant with time, at sometime during the five-year test the calibratjon values obtainerd on new stressmeters would became open to serious question.

Meaningful long-term corrosinn tests could not be peaformed in the time frame available; however, to improve the odds of stressmeter survival without significant corrosion, tnres steps were taken tu protec them:

(i) Prior to assembly, the stzessmeter oodies were plates inside and out with electroless nickei contajning $7 \%$ in $10 \%$ phosphorus. The plating was $0.127 \mathrm{~mm}$ thick an: was also applied to the platen.

(2) The stressmeter bodies were coated with $0.0167 \mathrm{~mm}$ of plastic film. After assembly of the strussmeters, the coating was applied covering all cracks, voids, and small holes and giving additional protection to thesf areas. 


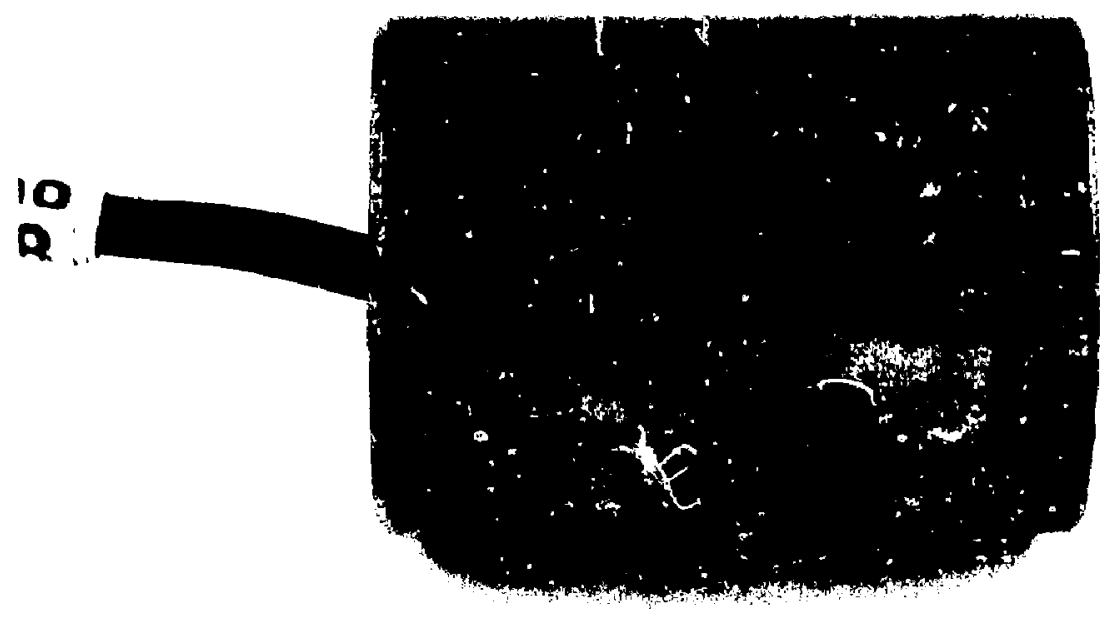

FIG. 3. Stressmeter from earlier in situ test snowing corrosion pits.

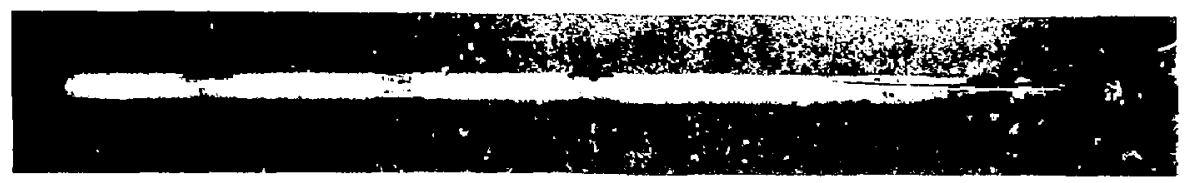

FIG. 4. Plastic tube with three dummy stressmaters foamed in latoratory test. 
(3) After the stressmeters were installed, the volume around the stressmeters was filled with a high density inert foam. This step was included to minimize the flow of groundwater around the stressmeters. The foaming operation was carried out several times in the laboratory under simulated field conditions. After tha technique was perfected, these tests were aiways successful. In Fig. 4, a plastic tube in which three dummy stressmeters were placed is shown after a simulated foaming operation.

We believe that this three-pronged approach will greatly reduce the amount of corrosion during the spent fuel test and will improve the validity of the stressmeter results. 
Eighteen IRAD GAGE vibrating-wire stressmeters were installed in the Spent Fuel Facility. Six stressmeter rosettes were used, each rosette consisting of three stressmeters. One was aligned at $0 \pm 0.10$ ( 0 is vertical for the horizontal hiles or perpendicular to the drift axis for the vertical holes), one was rotated $1.04 \pm 0.10 \mathrm{cCw}$, and the chird was rotated by $1.04 \pm 0.10 \mathrm{cW}$.

Prior to placing the stressmeters at the facility, a simple test that placed twi stressmeters in a borehole indicated that with. saparation of $150 \mathrm{~mm}$ the placement of the second stressmeter would not affect the preload of the first. The placement of the stressmeters is shown in Fig. 5. Boreholes NSG4 and NSG3 are horizontal holes and are located approximately $2 \mathrm{~m}$ above the floor in the pillar between the canister ar north heater drifts. Boreholes CSGl and CSG2 art vertical holes in the canister drift floor and are located approximately $1 \mathrm{~m}$ north of the row of canisters.

All boreholes are nominally $38 \mathrm{~mm}$ in diameter. All boreholes have distinct rifling with a wavelength of a few centimeters. The rifling is manifested as a decrease in diameter of a few tenths of a millimeter. In some cases, the boreholes also had gross failure zones. The stressmeters were placed in regians where no known gross damage exists; however, it is not possible to say that no damage exists in areas where the stressmeters were placed.

The installation was done with the modified IRAD GAGE installation tool. This tool allows, but certainly does not encourage, the installation of three stressmeters and one thermocouple in the same borehole. The installation was further complicated by the north-heater-drift narrowness, which made it 


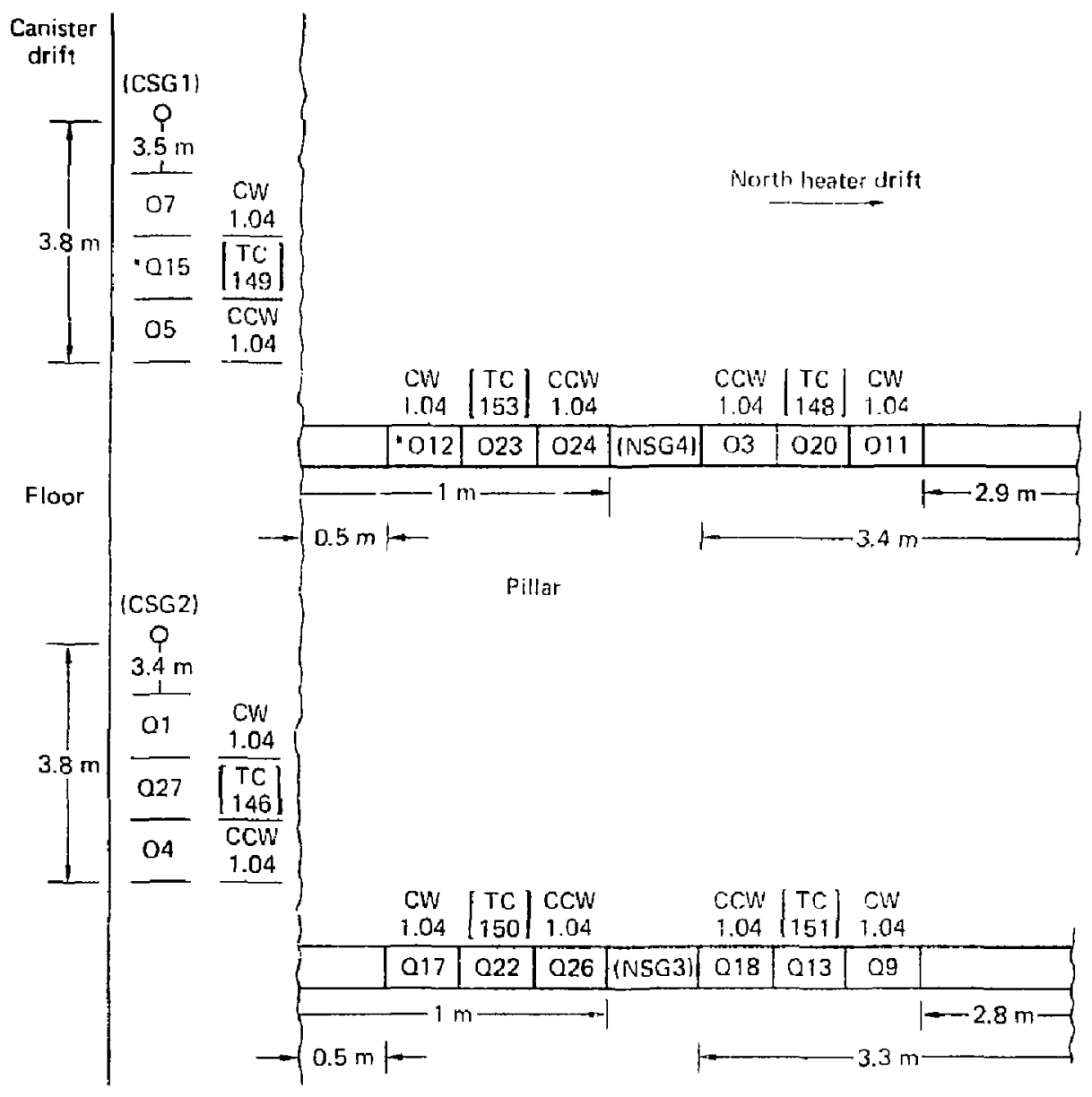

FIG. 5. Stressmeter placements (CW, cluckwise; CCW, counterclockwise; TC, thermocouple; also, hole designations are given in parentheses). 
necessary to insert the stressmeters part way into the borehole before the installation tool could be completely assembled.

A list of the stressmeter placements is given in Table 1. Also in the table are zero load periods, the preload period with the tool in place, the preload period after tool withdrawal, the preload difference, and the percent change. After placement, the rosettes were foamed. There is no independent way of checking the success of the foaming, but secondary indications were encouraging. Comparison with our laboratory studies indicates that two stressmeters, NSG44 and GSG12, had probably platen-wedge shift and that two other5, USG31 and NSG35, are suspect.

For the stressmeters with a small (10\%) drop in preload upon removal of the installation taol, we recommend that the standard IRAD GAGE ${ }^{2}$ caliuration be used because of the larger stress range covered and the rela':ively simple stress state used in their experiments. The IRAD GAGE calibration is:

$$
{ }_{r}=A\left[1-\left(\frac{T_{0}}{T}\right)^{2}\right]\left[\frac{422400}{T_{0}}\right]^{2} \mathrm{~Pa},
$$

where $I$ is the stress change, $T_{0}$ is the preload period, and $T$ is the period. For the standard calibration, $A=1.6 \times 10^{4}$. If the preload dropped the order of $10 \%$ or more, we recommend a $30 \%$ less sensitive calibration ( $\left.A=2 \times 10^{4}\right)$.

An alternate approach would be to use an average calibration for all stressmeters $\left(A=1.0 \times 10^{4}\right)$. If this were done the stressmeter calibrations would be within $\pm 15 \%$. In making these recommendations we are assuming that the stressmeters placed at the Spent Fuel Facility behaved in the same manner as those in the laboratory. 
TABLE 1. Stressmeter parameters.

\begin{tabular}{|c|c|c|c|c|c|c|c|c|c|c|}
\hline Hole & No. & Position & $\begin{array}{l}\text { TRAO } \\
\text { No. }\end{array}$ & $\begin{array}{l}\text { Zero } \\
\text { load } \\
\text { reading }\end{array}$ & $\begin{array}{l}\text { Tool } \\
\text { in } \\
\text { place }\end{array}$ & $\begin{array}{l}\text { Too } 1 \\
\text { removed }\end{array}$ & 1 & $n_{3}$ & Thermocouple & $\begin{array}{l}\text { Thermocouple } \\
\text { no. }\end{array}$ \\
\hline NSG4 & $\begin{array}{l}3 \\
2 \\
1 \\
6 \\
5 \\
4\end{array}$ & $\begin{array}{l}\text { Deep } \\
\text { Mid } \\
\text { Shal low } \\
\text { Deep } \\
\text { Mid } \\
\text { Shallow }\end{array}$ & $\begin{array}{l}03 \\
020 \\
011 \\
024 \\
023 \\
012\end{array}$ & $\begin{array}{l}1878 \\
2200 \\
2181 \\
2200 \\
2121 \\
2072\end{array}$ & $\begin{array}{l}2090 \\
2405 \\
2429 \\
2404 \\
2349 \\
2275\end{array}$ & $\begin{array}{l}2089 \\
2391 \\
2421 \\
2394 \\
2343 \\
2240\end{array}$ & $\begin{array}{r}1 \\
14 \\
8 \\
10 \\
6 \\
35\end{array}$ & $\begin{array}{r}0 \\
7 \\
3 \\
5 \\
3 \\
17\end{array}$ & $\begin{array}{l}\text { SGTOA I } \\
\text { SGT044 }\end{array}$ & $\begin{array}{l}148 \\
153\end{array}$ \\
\hline NSG3 & $\begin{array}{l}\mathbf{3} \\
2 \\
1 \\
\mathbf{5} \\
\mathbf{5} \\
4\end{array}$ & $\begin{array}{l}\text { Deep } \\
\text { Mid } \\
\text { Shallow } \\
\text { Deep } \\
\text { Mid } \\
\text { Shallow }\end{array}$ & $\begin{array}{l}Q 18 \\
013 \\
09 \\
Q 26 \\
Q 22 \\
q 17\end{array}$ & $\begin{array}{l}1918 \\
1837 \\
2122 \\
2028 \\
2177 \\
2186\end{array}$ & $\begin{array}{l}2122 \\
2058 \\
2322 \\
2230 \\
2397 \\
2416\end{array}$ & $\begin{array}{l}2122 \\
2042 \\
2300 \\
2222 \\
2372 \\
2401\end{array}$ & $\begin{array}{r}0 \\
16 \\
22 \\
8 \\
25 \\
15\end{array}$ & $\begin{array}{r}0 \\
7 \\
11 \\
4 \\
11 \\
7\end{array}$ & $\begin{array}{l}\text { SGT031 } \\
\text { SGT034 }\end{array}$ & $\begin{array}{l}151 \\
i 50\end{array}$ \\
\hline $\operatorname{CSG} 2$ & $\begin{array}{l}3 \\
2 \\
1\end{array}$ & $\begin{array}{l}\text { Jeep } \\
\text { Mid } \\
\text { Shal low }\end{array}$ & $\begin{array}{l}\text { Q4 } \\
\text { Q27 } \\
\text { QI }\end{array}$ & $\begin{array}{l}1924 \\
1839 \\
2188\end{array}$ & $\begin{array}{l}2129 \\
2053 \\
2397\end{array}$ & $\begin{array}{l}2124 \\
2035 \\
2398\end{array}$ & $\begin{array}{r}5 \\
18 \\
1\end{array}$ & $\begin{array}{l}2 \\
8 \\
0\end{array}$ & SGF021 & 146 \\
\hline $\operatorname{cs} 61$ & $\begin{array}{l}3 \\
2 \\
1\end{array}$ & $\begin{array}{l}\text { Deep } \\
\text { Mid } \\
\text { Shallow }\end{array}$ & $\begin{array}{l}05 \\
\text { Qis } \\
07\end{array}$ & $\begin{array}{l}2075 \\
2018 \\
2049\end{array}$ & $\begin{array}{l}2232 \\
2033 \\
2389\end{array}$ & $\begin{array}{l}2227 \\
2205 \\
2384\end{array}$ & $\begin{array}{r}5 \\
28 \\
5\end{array}$ & $\begin{array}{r}2 \\
13 \\
1\end{array}$ & SGT011 & 149 \\
\hline
\end{tabular}


Several areas could be investigated in the future. Such investigation would expand our understanding of the results from the present test and prepare for future tests. The following are the areas:

(1) Interactions between individual stressmeters in a stressmeter rosette.

(2) Determination of calibrations of stressmeter rosettes in large blocks with a triaxial stress state.

(3) Long-term corrosion studies.

(4) The effect of corrosion on calibration.

(5) Detailed studies of the effect of stressmeter assembly aligrment.

(6) Modification of stressmeter geometry to minimize the effect of assemoiy alignment.

(7) Improvernent of the design of the installation tool to make it easier to use and to allow better alignment of the stressmeter assembly--borehole system. The installation tool should also be modified to allow the preload to be both increased and decreased. With this modification, the first stress cycles could be done in place, and therefore the stressmeter could be assumed to be "set in." 


\section{ACKNOWLEDGMENTS}

We would like to thank R. C. Carlson, T. C. Roy, and B. MCNeill for their assistance in the installation of the stressmeters at the Spent Fuel Facility. 
1. L. D. Ramspett, L. B. Ballou, R. C. Carlson, D. N. Montan, T. R. Butkovich, J. E. Duncan, W. C. Patrick, D. G. Wilder, W. G. Brough, and M. C. Mayr, Technical Concept For A Test of Geologic Storage of Spent Reactor Fuel In The Climax Granite, Nevada Test Site, Lawrence Livermore Laboratory, Livermore, CA, UCRL-52796 (1979).

2. I. Hawkes and w. V. Bailey, Design, Develop, Fabricate, Test, and Demonstrate Permissible Low Cost Cylindrical Stress Gages and Associated Components Capable of Measuring Changes of Stress as a Function of Time in Underground Coal Mines, Creare, Inc., Tech. Rept., USBM Contract No. H0220050, November 1973.

3. R. W. Hatfield, "Repeatability Study of IRAO GAGE Stressmeter," IRAD GAGE, Inc., Lebanon, NH, Technical Memo TM 79-20, December 1979. 